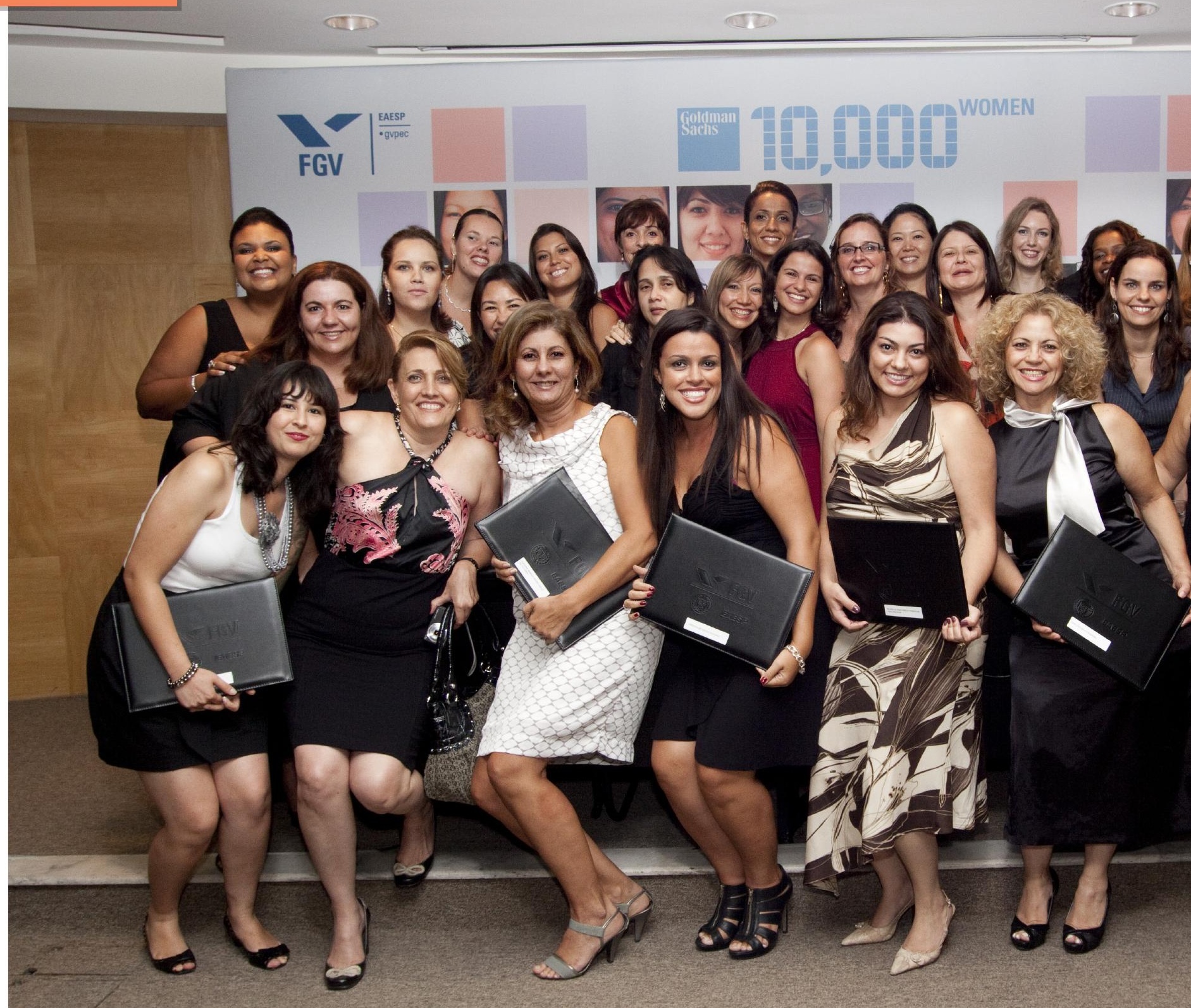

\title{
10.000 MULHERES: \\ EMPREENDEDORISMO \\ FEMININO EM FOCO
}




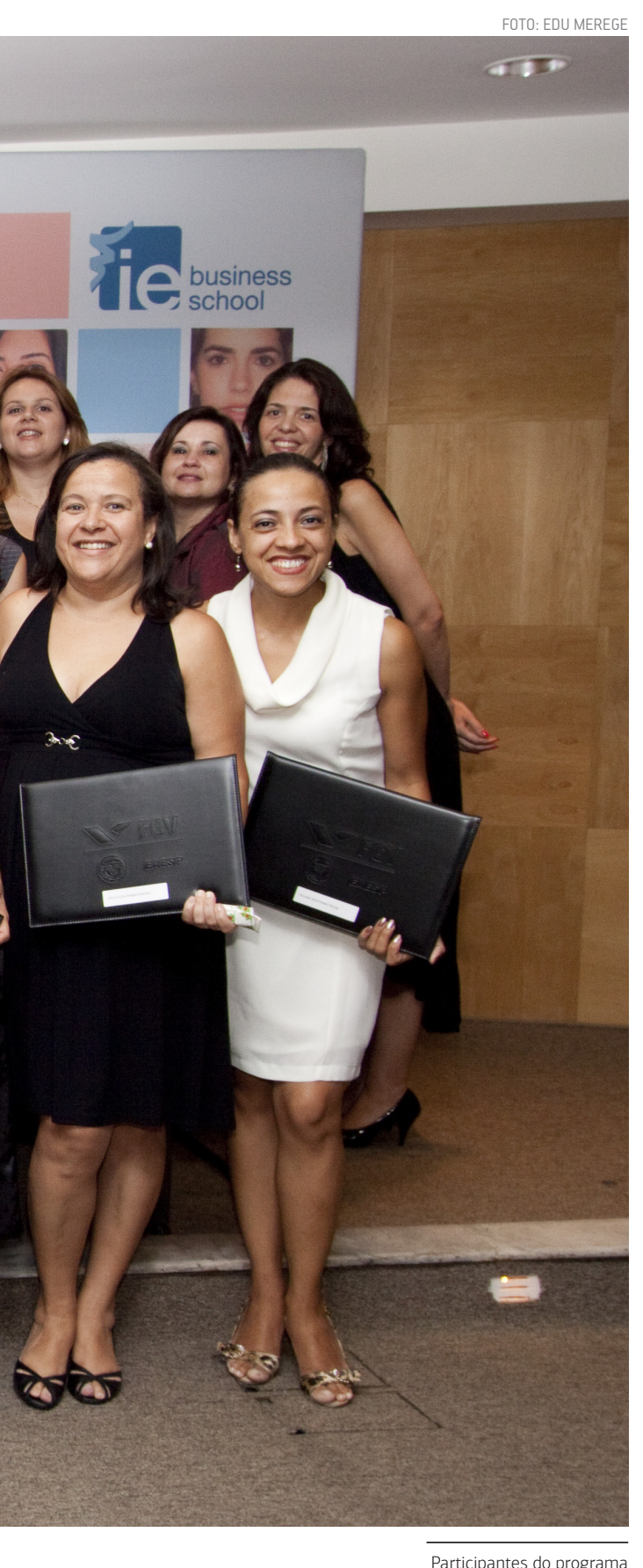

10.000 Mulheres
POR REDAÇÃO GV-EXECUTIVO

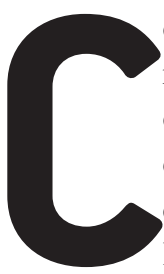

onsiderando o atual panorama econômico do Brasil, o empreendedorismo é uma das atividades que mais crescem no país, e as mulheres têm surpreendido positivamente quando o assunto é a abertura do próprio negócio.

De acordo com um estudo recente realizado pela London Business School, Babson College, Serviço de Apoio às Micro e Pequenas Empresas (Sebrae) e Instituto Brasileiro de Qualidade e Produtividade (IBQP), dos mais de 21,1 milhões de empreendedores no Brasil, 49,3\% são do sexo feminino. Pode-se notar o desenvolvimento do setor entre este público se considerarmos o fato de que, há 10 anos, 57,6\% dos empreendedores eram homens e 42,4\% mulheres.

Com o objetivo de incentivar esta atividade e fornecer educação de qualidade às mulheres que já têm seu negócio em funcionamento, a FGV-EAESP, em parceria com a IE Business School, renomada escola espanhola de gestão, criou um programa que proporciona às participantes o conhecimento e as ferramentas necessárias para obter sucesso e saber como lidar com a competição no mercado local e global.

A iniciativa da FGV faz parte do programa 10.000 Mulheres. Lançada em 2008, pela Goldman Sachs e Goldman Sachs Foundation, a ação oferece gratuitamente ensino em administração e gestão de negócios a dez mil mulheres de áreas carentes em todo o mundo, ajudando a melhorar a qualidade do conhecimento empresarial nos países em desenvolvimento.

No Brasil, mil empresárias podem participar da capacitação, que conta com aulas de empreendedorismo e serviços de apoio ao empreendedor para que possam alavancar seus negócios. Além disso, elas também têm acesso a atividades complementares, como orientações online, tutoria e mentoring, eventos de networking e fóruns abertos, que lhes permitirão aprender e trocar ideias.

De acordo com a vice-diretora da FGV-EAESP, Maria José Tonelli, coordenadora do projeto juntamente com o professor Tales Andreassi, o 10.000 Mulheres está sob total responsabilidade da Escola há três anos e já beneficiou muitas participantes. "Trata-se de um projeto que temos muito orgulho de participar, pois atende mulheres que não teriam condições de pagar um curso de extensão. Sete turmas já concluíram o programa na EAESP e podemos dizer que ele foi muito bem sucedido, pois as alunas foram incentivadas a desenvolver seus negócios, permitindo a interação entre professores e empreendedoras, além de possibilitar o ganho de conhecimento por parte da Escola, com a construção de um currículo totalmente desenhado para este grupo", explica Maria José.

Além de todo o apoio durante o curso, o projeto também acompanha o desempenho das participantes após a finalização da turma. "A Goldman Sachs, patrocinadora da iniciativa, desenvolveu um sistema para monitorar a evolução do negócio das participantes por até três anos após o término do curso. A maioria prospera significativamente. É interessante também que algumas mulheres, após as aulas, identificam outras oportunidades de negócio, abrindo uma nova empresa e fechando a antiga", destaca o professor Andreassi.

O processo de seleção é realizado pela própria FGV. Para se inscrever ou obter mais informações sobre o programa basta entrar no site www.10000mulheres.com.br 